Division of Agricultural sciences

UN I VERSITY OF CALIFORN I A

\title{
Principles of
}

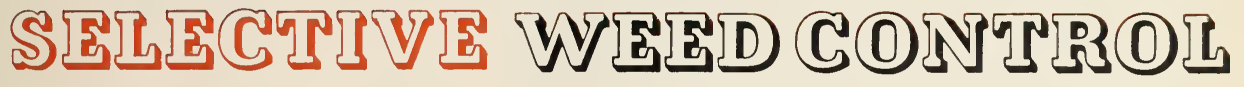

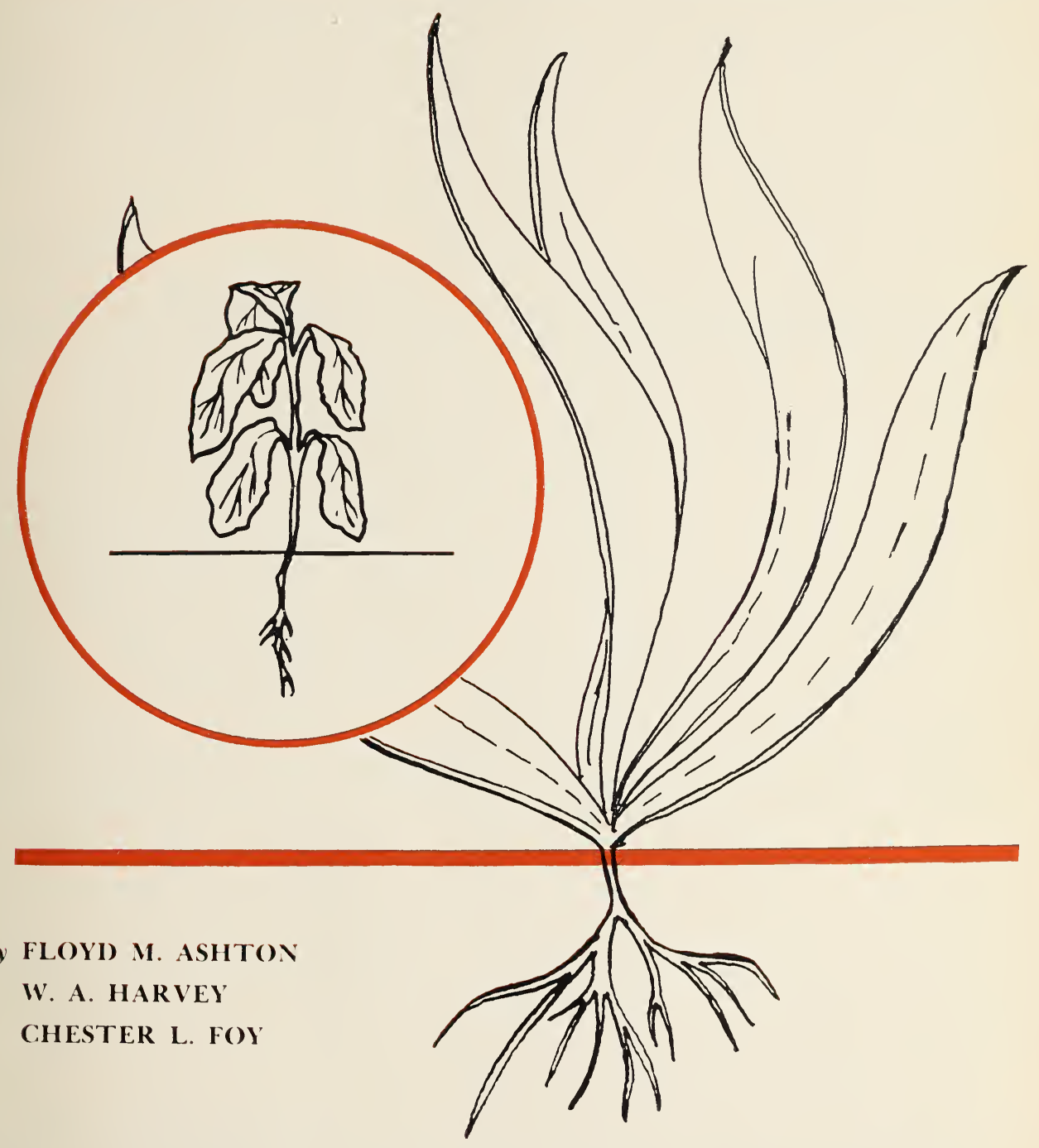

CALIFORNIA AGRICULTURAL

Experiment $S$ tation

CIRCULAR 505

Extension Service 
Selective chemical weed control uses a herbicide to control weeds in a crop without injuring the crop. The chemical "selects" the weed and destroys it because of either a quality inherent in the herbicide or because of the way a nonselective herbicide is used. Selectivity is relative: it depends on proper use of the herbicide. It will work only within a given range of concentration of the herbicide and under particular conditions.

This circular explains the principles of how herbicides are used on foliage and soil (pages 4 and 5), indicates how herbicides work selectively to kill weeds while keeping crops alive (pages 5 to 15), and suggests how to apply selective herbicides (pages 16 and 17). Also included are a glossary of terms used in selective weed control (pages 17 to 19) and a list of free publications on weed control (pages 19 and 20).

DECEMBER, 1961 


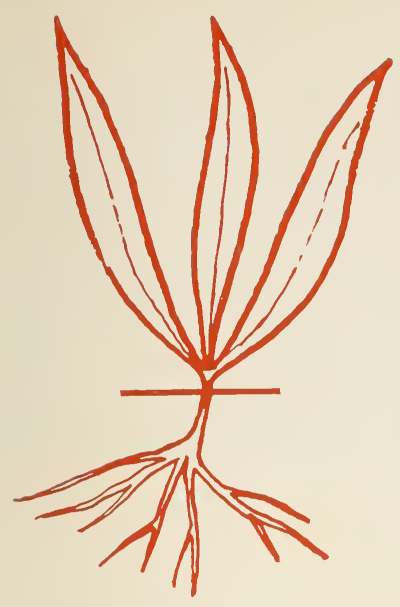

Principles of

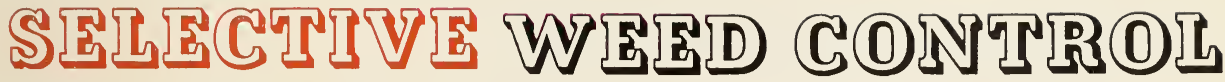

FLOYD M. ASHTON, W. A. HARVEY and CHESTER L. FOY

P eeds are costly. They take water, fertilizer, and light from the crop plants. They often reduce yield and quality of crop and livestock products. They increase labor and equipment costs, harbor insect and disease organisms, and reduce land values. The cost of weeds to the American farmer is estimated at $\$ 5,000,000$,000 annually. Losses in California alone have been estimated at $\$ 1,000$,000 per day. In certain crops the losses due to weeds can exceed $\$ 100$ per acre. In many crops these losses can mean the difference between success and failure to the grower.

\section{HOW LOSSES ARE REDUCED}

Losses can be reduced by three principal means-weed prevention, eradication, and control.

\section{Weed Prevention}

Weed prevention means primarily good farm sanitation. You start out with weed-free fields, and prevent weeds from being introduced and from spreading. Preventive methods include the use of clean seed, cleaning contaminated equipment, keeping fence row and ditch bank weeds from seeding and spreading, and spot-treating small weed infestations within the field.

\section{Weed Eradication}

Weed eradication completely destroys or removes all weed plants including regenerative plant parts. Eradication is sometimes justifiable, as in the case of small new infestations of particularly troublesome weeds, even at relatively high costs per unit area or loss of selectivity. 


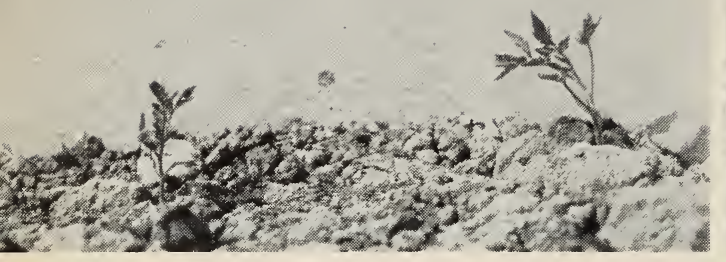

Correct application of selective herbicide kills

1. Too much herbicide killed the watergrass but badly damaged the tomato crop.

\section{Weed Control}

Weed control is in most instances the most reasonable approach. Many weeds are so widespread that eradication, though desirable, becomes economically impractical. But you can reduce the infestation to a level that will enable you to produce a crop profitably in spite of the weeds.

\section{CONTROL METHODS}

Mechanical Control

Mechanical weed control includes cultivation, mowing, burning and hoeing; even hand pulling is justified under some conditions.

\section{Cropping Control}

Cropping methods take advantage of crop rotation to obtain changes in the environment which will keep weeds down. Often the new crop successfully competes with the weeds from the previous crop. Sometimes other methods of weed control combine with cropping, as for example the use of 2,4-D in grain following a 2,4-D-sensitive crop in which broadleaved weeds have become a problem.

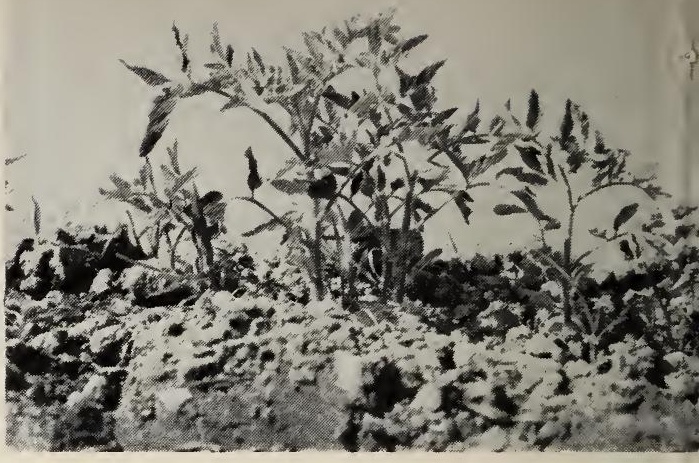

watergrass while leaving the tomato crop intact:

2. Correct application killed the watergrass without damage to the crop.

\section{Biological Control}

Biological methods use living organisms, mostly insects, to control weeds. Examples are the Chrysolina spp. beetle to control Klamath weed on California ranges, and the use of geese in cotton for control of grasses.

\section{Chemical Control}

Weed control by chemicals offers the greatest potential. It is not new but has been extensively developed only for the past several years.

Any one method of weed control is not enough; it takes the intelligent integration of all of these methods into a long-range, over-all program to obtain the maximum return for your money and effort.

\section{HOW HERBICIDES ARE USED}

Herbicides are used either on the foliage or in the soil.

\section{Foliage Applications}

These treatments are made to leaves of growing plants, usually as liquid sprays. They kill plants by two methods-contact or translocation. 

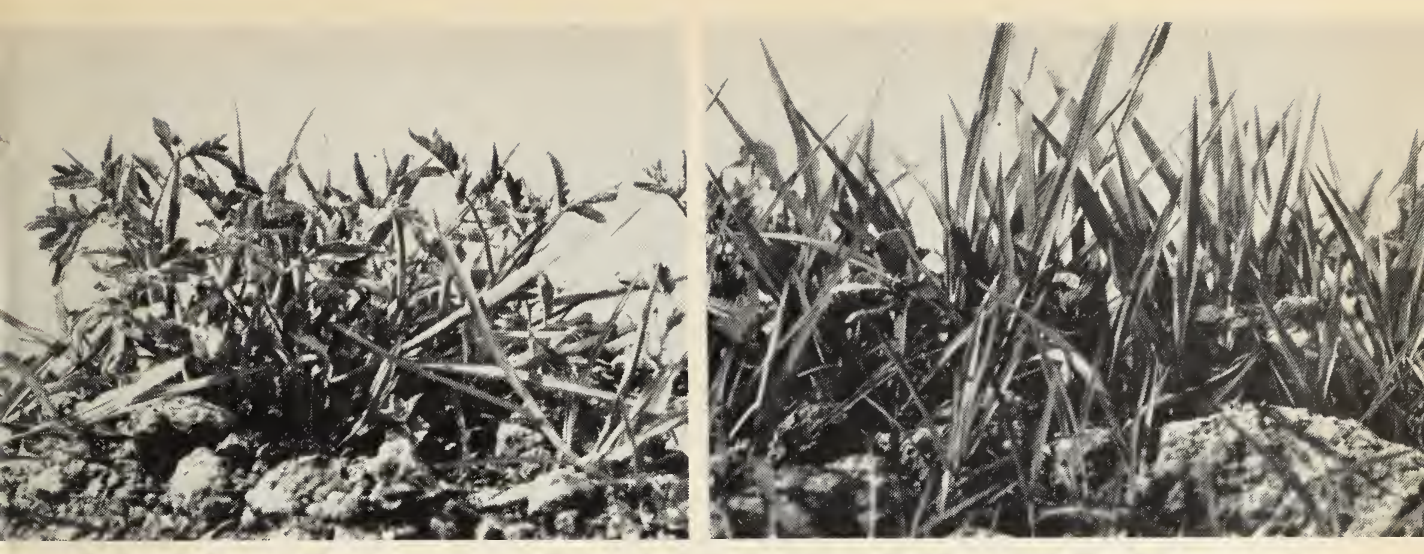

3. Too low a rate of herbicide left some water4. No control-the watergrass has taken over. grass.

By Contact. This treatment kills only the plant parts actually contacted by the herbicide. However, the noncontacted parts (i.e. roots) may die because they are deprived of the essential contacted organs (i.e. leaves). Adequate distribution of the herbicide over the foliage is essential. Selectivity may depend upon arrangement and angle of leaves, differential wetting, location of growing points, or upon spray placement. Contact herbicides are most useful to control seedlings.

By Translocation. This treatment kills the entire plant since the herbicide moves within the plant. For example, when applied to the leaves the herbicide is translocated to the roots. It may also move from older leaves to young growing points. Therefore, herbicides of this type are used on perennial plants as well as annuals. Selectivity depends primarily on physiological differences between plants but in some instances upon timing of the application in relation to planting the crop.

\section{Soil Applications}

These treatments are usually applied to the surface of the soil but may also be incorporated into the soil by cultivation, or injected below the soil surface.

Timing of the application in relation to the growth stage of the weeds and crop is important. The application may be made pre-plant, pre-emergence or post-emergence as related to the growth stage of the crop plant.

Surface moisture must follow surface treatments for soil-applied herbicides to be effective; you will obtain best results when these herbicides are carried into the soil by rainfall, overhead irrigation, or flood irrigation. A physical incorporation of the surfaceapplied herbicide into the top 2 inches of soil followed by the furrow irrigation is usually as effective as rainfall or overhead irrigation.

\section{BASES OF SELECTIVITY}

Listed in this section are the principal factors which contribute toward 
herbicidal selectivity. These processes, however, are not mutually exclusive. The choice of a herbicide for a certain crop-weed combination is of ten determined by several factors.

\section{Leaf Properties}

Certain leaf properties will protect the crop treated by a selective herbicide (see drawings below and at right). Such protective properties are narrow, upright leaves, as of cereals and onions, waxy leaf surfaces, or leaves that are corrugated or formed of very small ridges. Water droplets can stick to only a small portion of these surfaces. When water sprays hit such leaves they bounce off in droplets or wet the surface only in small spots.

Broad-leaved plants have wide smooth leaf surfaces, extending horizontally from the plant stem. Such leaves intercept more of the spray which spreads over them and does not bounce off.
Therefore, when broad-leaved weeds such as lambs' quarters, wild radish, pigweed, or wild mustard are sprayed with contact herbicides, the spray solution tends either to spread as a thin film or to remain as many small droplets that wet a large portion of the leaf, thus surface-killing the weed. The same spray on cereals or onions tends to bounce off leaving the crop plants uninjured.

WARNING: The addition of surfactants or other additives to increase the effects of herbicides based on this principle may eliminate their selectivity.

\section{Location of Growing Points}

The growing points of cereals are located at the base of the plant and are protected from contact herbicides by the surrounding leaves. In some cases they are actually below the soil surface. Therefore, any contact spray remaining on the cereals may injure

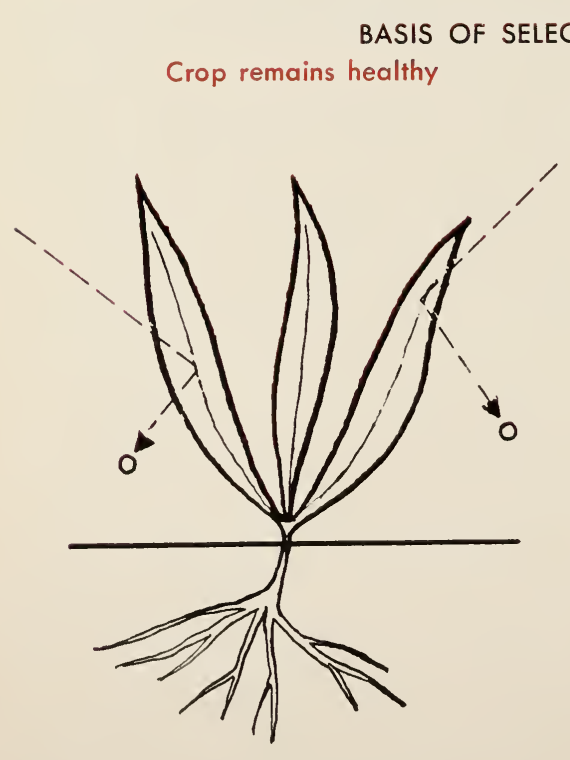

On narrow upright leaves spray bounces off, does not affect plant. 
Crop remains healthy

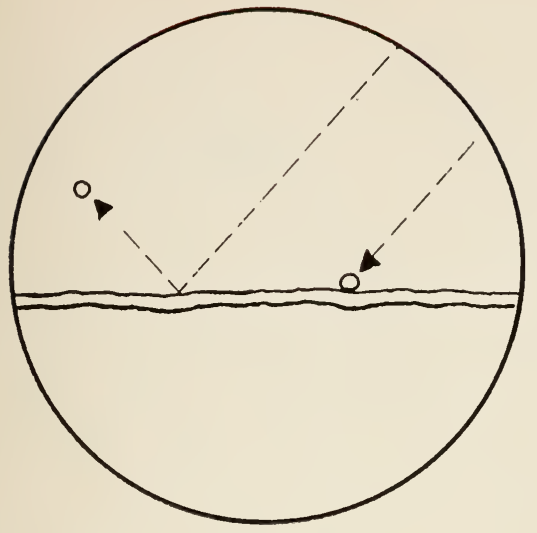

On waxy leaves, spray bounces off or forms discrete droplets.
Weed is killed

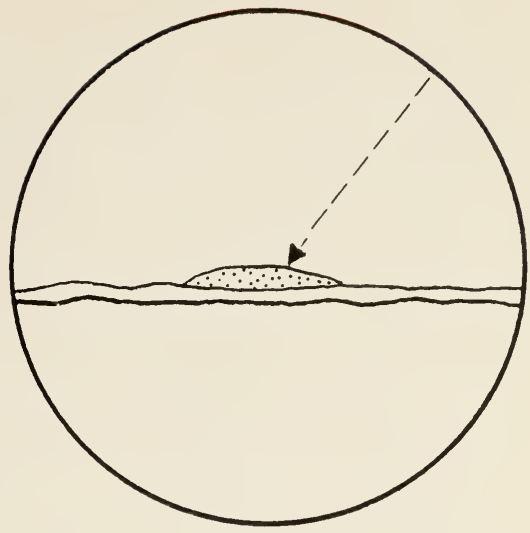

On nonwaxy leaves, spray sticks and spreads.

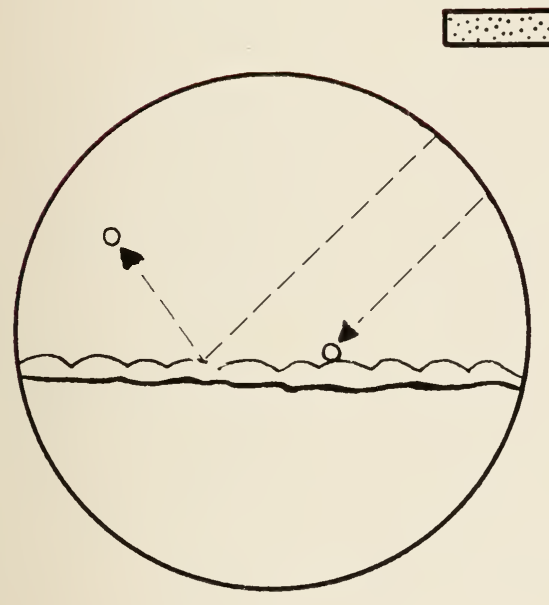

On corrugated leaves, spray bounces off or forms discrete droplets.
HERBICIDE

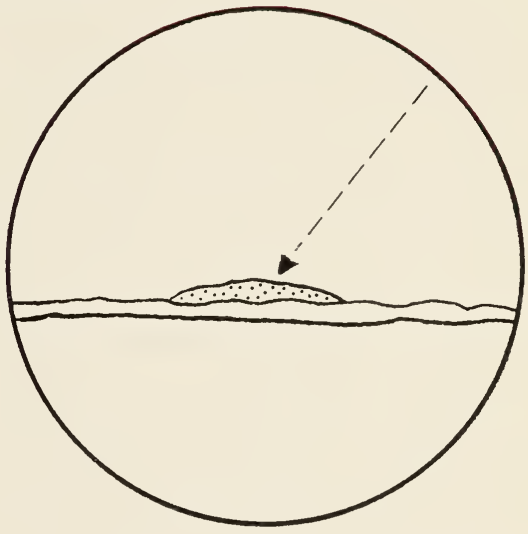

On noncorrugated leaves, spray sticks and spreads. the leaves but will not contact the growing points. (See drawing on page 8.)

Broad-leaved plants, in contrast, have exposed growing points at the tips of the shoots and in the leaf axils. With this type of plant the contact herbicide actually strikes the growing point.

\section{Growth Habits}

Annual weeds in a field of perennial crops can be controlled because the perennial crop, e.g. alfalfa, has a deep extensive root system. Such root systems will recover from moderate injury to parts above ground whereas annual weeds, having shallow roots, will be killed (see drawings on page 


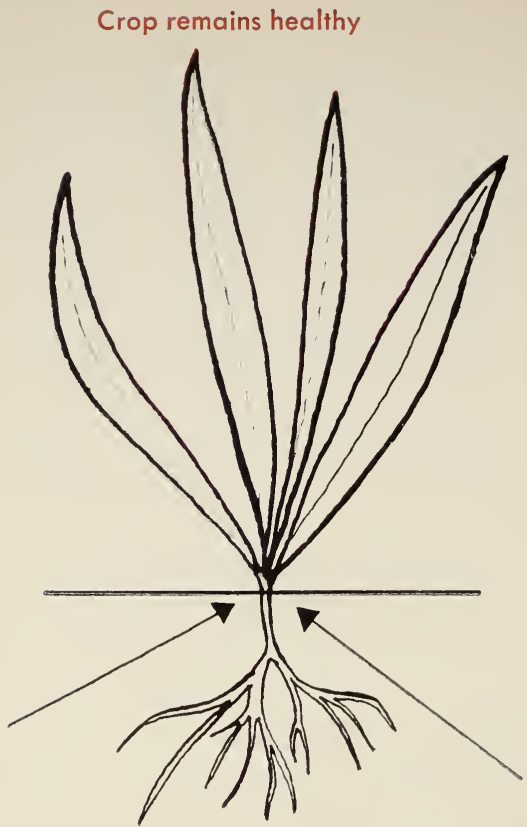

Growing points (arrows) are protected from the spray.

9). To reduce injury of the alfalfa to a minimum, apply the herbicide during the winter (dormant period) or immediately after cutting. The type of herbicide used in this method of control is a general-contact spray.

\section{Absorption}

Absorption is the movement of a material into the plant (usually the leaves and roots) from an external source. The absorption of herbicides by plants is not the same in all species nor even at all ages of the same species. This difference in absorption can be used in selective weed control (see drawings on page 9). Plants absorb herbicides through the cuticle, the stomata, or both.

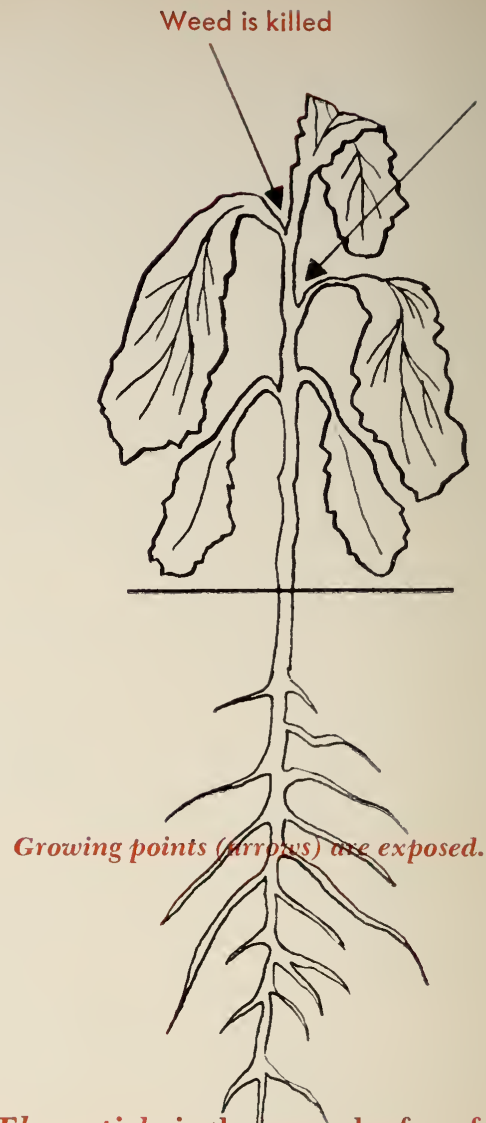

The cuticle is the waxy leaf surface. The thickness and hature of the cuticle varies from species to species with age of plant, and within the same species with environmental conditions. Plant leaves growing in the shade have a thinner cuticle than those exposed to full sunlight. Young leaves have thinner cuticle than older leaves. The cuticle acts as a major barrier to the absorption of herbicides by plants. Therefore, plants with a thin cuticle absorb a considerable amount of the herbicide and are killed; plants with a thick cuticle absorb little or none of the weedkiller and survive.

The stomata (the microscopic pores on the leaf surface) vary in location, 
BASIS OF SELECTIVITY: Growth Habits

Crop recovers

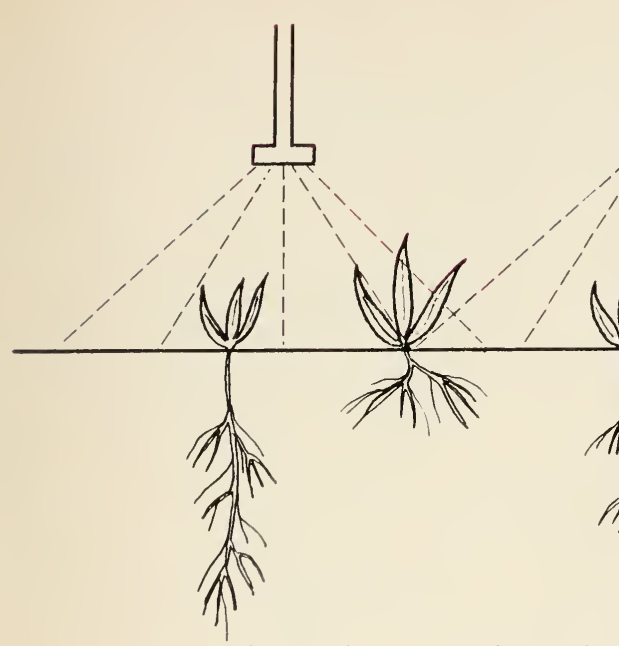

Crop roots 1, 3, and 5 are deep, extensive, and therefore recover from surface spray.
Annual weed is killed

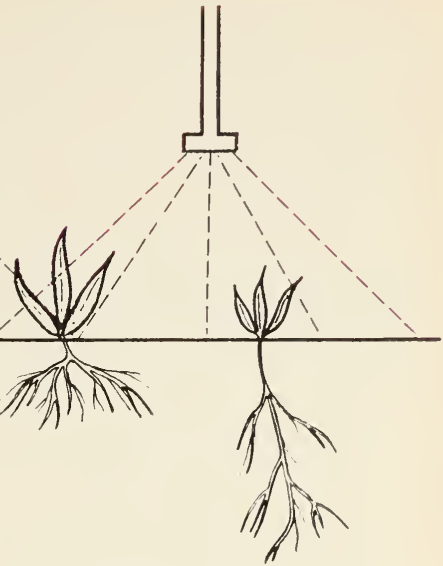

Weed roots 2 and 4 are close to surface, easily killed by contact sprays.

number and size in the various plant species. In many plants they are located on both upper and lower leaf surfaces; in others only on the lower surface. The number of stomata per unit area varies as much as tenfold among species. Stomata size varies as much as five- or six-fold among species. Obviously, plants with many, large stomata on both leaf surfaces will be

killed by absorption of herbicide, while those with few small stomata may survive.

Wetting agents in herbicide formulations primarily are used to increase their killing properties by increasing absorption. Suitable wetting agents mainly increase absorption through the stomata, but to some extent probably also through the cuticles.

BASIS OF SELECTIVITY: Absorption
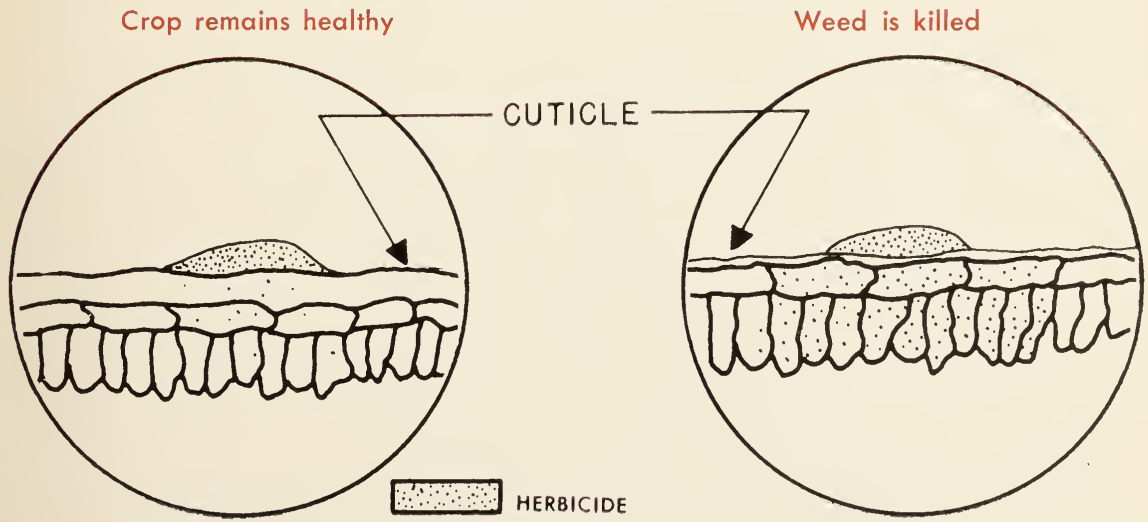

Thick cuticle prevents absorption of herbicide.

Thin cuticle permits good absorption of herbicide. 


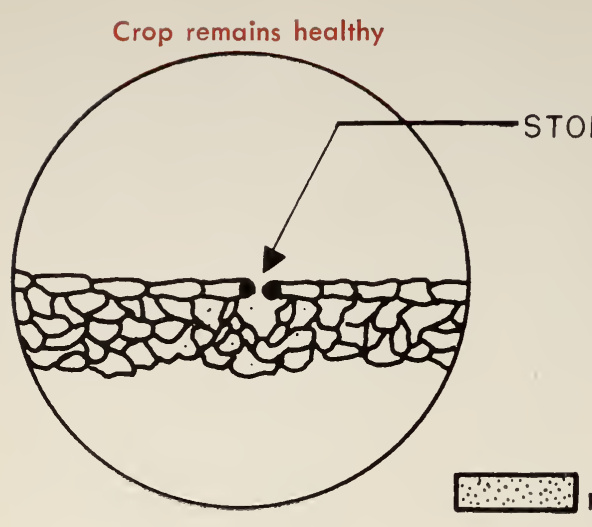

Few small stomata permit only poor absorption of herbicide.

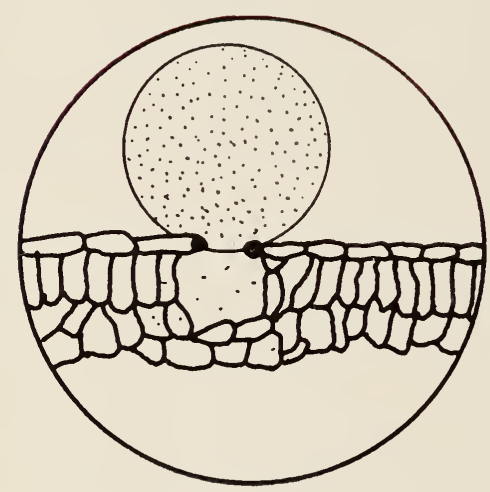

No wetting keeps stomatal absorption low.

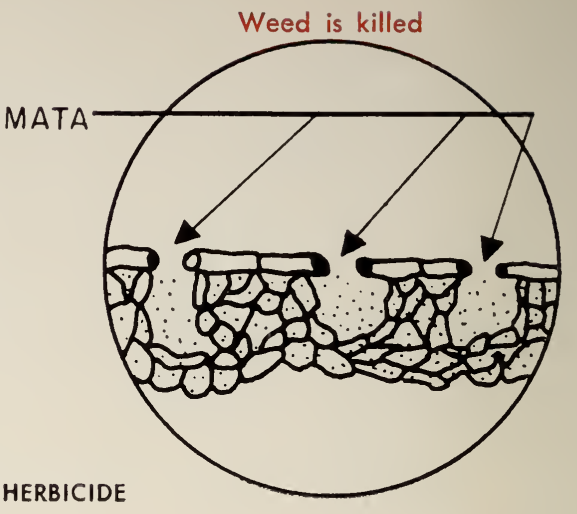

Many large stomata allow good absorption of herbicide.

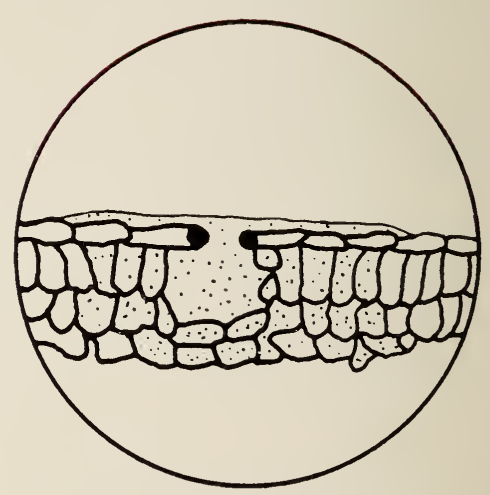

Wetting agent favors good stomatal absorption.

\section{Translocation}

Once a herbicide has entered a plant (absorption) it must move from the point of absorption to other parts of the plant to exert its maximum effect. This movement from the point of absorption to the various sites of action is one example of translocation.

Translocation occurs both upward from the roots to the plant parts above the soil, and downward from the leaves to the underground parts of the plant. Translocation rate and the amount of herbicide translocated vary with different herbicides, and among plant species; they even vary within a given species under different environmental conditions. Rate and amount of translocation of 2,4-D, for example, are greater in susceptible species than in resistant species. These differences are used in applying selective herbicides (see drawings on opposite page). 
BASIS OF SELECTIVITY: Translocation

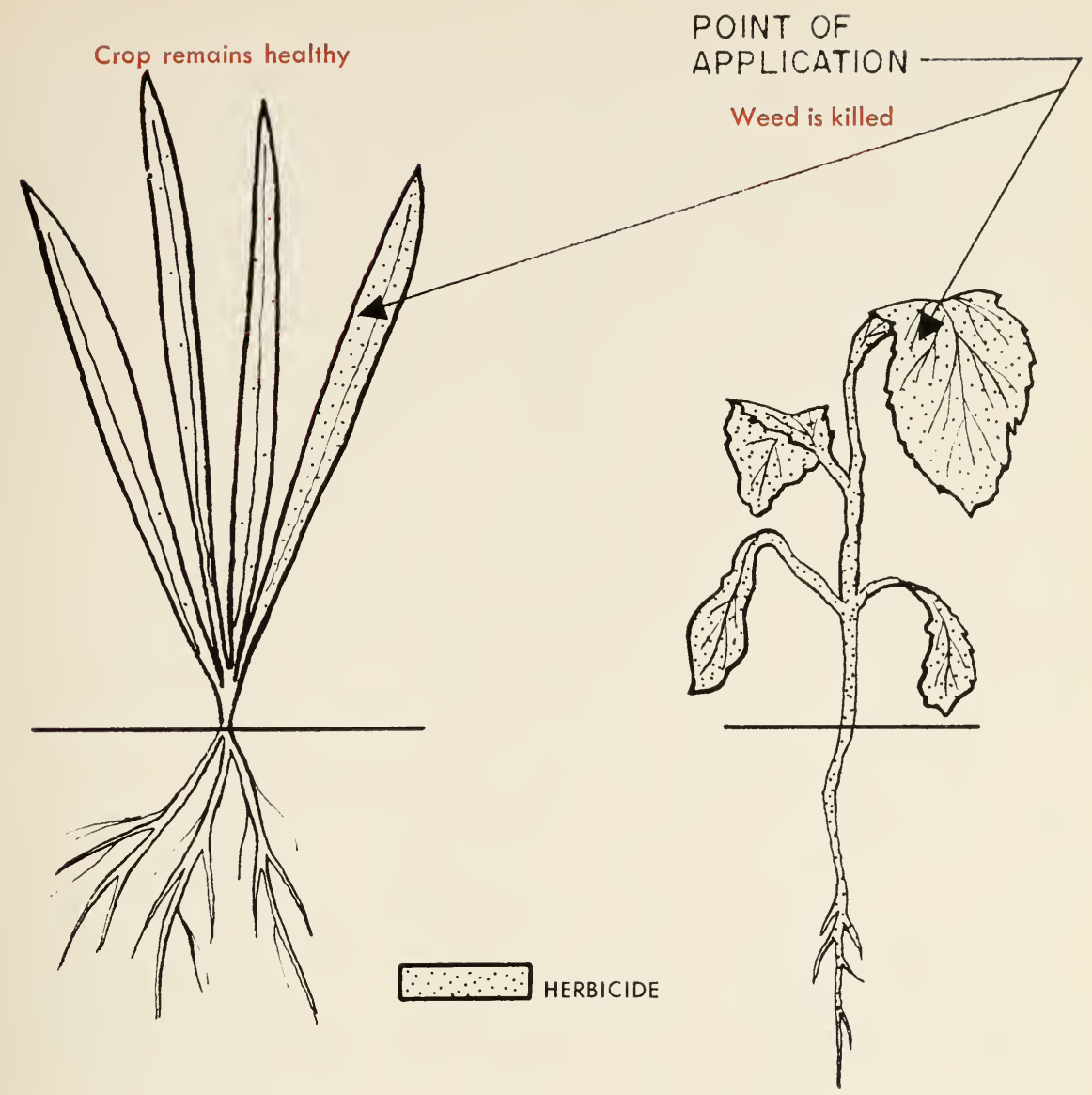

Poor translocation of 2,4-D in grasses make them resistant to weed killer.

Biophysical-Biochemical

The five major explanations for this type of selectivity are shown in the drawings on pages 12-13.

Adsorption of the herbicide by the cells inactivates the material probably by a physical rather than a biochemical process. Extensive radioactive tracer studies have shown that herbicides are held and their movement slowed down by the surrounding plant tissues. In extreme cases, the herbicide may be so tightly bound to some plant constituent that it is not readily trans-
Good translocation of 2,4-D in broad-leaved weeds make them susceptible to weed killer.

located from the point of application to the site of action or that even at the site of action it is so tightly held that it is unavailable for herbicidal action.

Oil toxicity in carrots and related crops is one of the oldest examples of biophysical-biochemical selectivity.

The selective oils used for weed control in carrots kill weeds by damaging the cellular membranes and allowing the cell sap to flow into the intercellular spaces. This causes death of the cells and the tissue dries out. The carrots are not killed because the 
cellular membranes are resistant to this damage.

Enzyme reaction sometimes is blocked by the herbicide in one plant species but not in another, thereby selectively interfering with one or more normal metabolic processes. This phenomenon can be used to kill certain plants while leaving others unharmed. Dalapon, for example, inhibits one of the B-complex vitamins. The vitamin pantothenic acid constitutes a vital part of the important coenzyme $\mathbf{A}$, a key compound in plant metabolism. Plant species apparently differ in ability to withstand dalapon inhibition of pantothenic acid synthesis.

Activation of a harmless chemical into a plantkiller sometimes can be used in selective weed control. For example, the relatively harmless compound 2,4-DB is changed in some sensitive plants into the weedkiller 2,4-D, while in resistant plants (e.g. alfalfa) no such change takes place.

Decomposition of a herbicide into a harmless compound by some plants also can be used. One of the best examples of this principle is the ability of corn to decompose the herbicide simazine. The corn plant decomposes the herbicide and carbon dioxide gas is given off by the plant. This protects corn from accumulating lethal amounts of this herbicide. Many other plants lack this ability to break down the herbicide and are killed.

\section{BASIS OF SELECTIVITY: Biophysical-Biochemical}

Adsorption

Crop remains healthy

Weed is killed

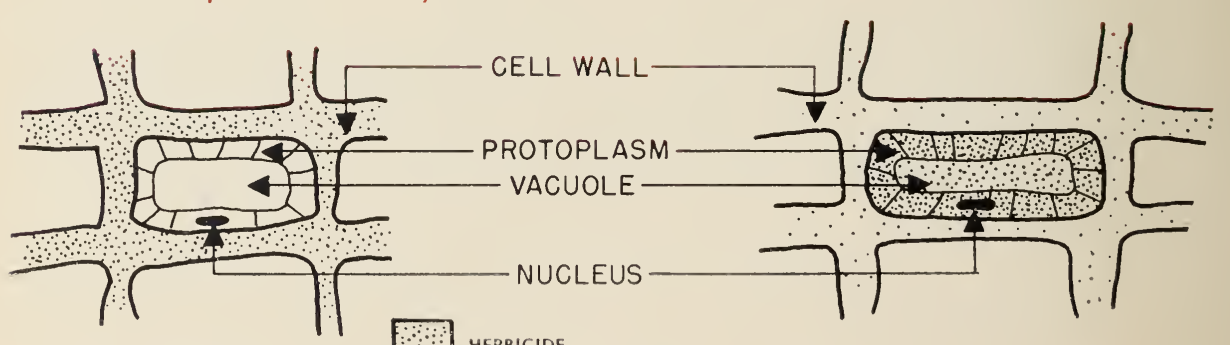

Herbicide is adsorbed by cell wall, and is prevented from reaching protoplasm.

Herbicide not adsorbed by cell wall, reaches protoplasm.

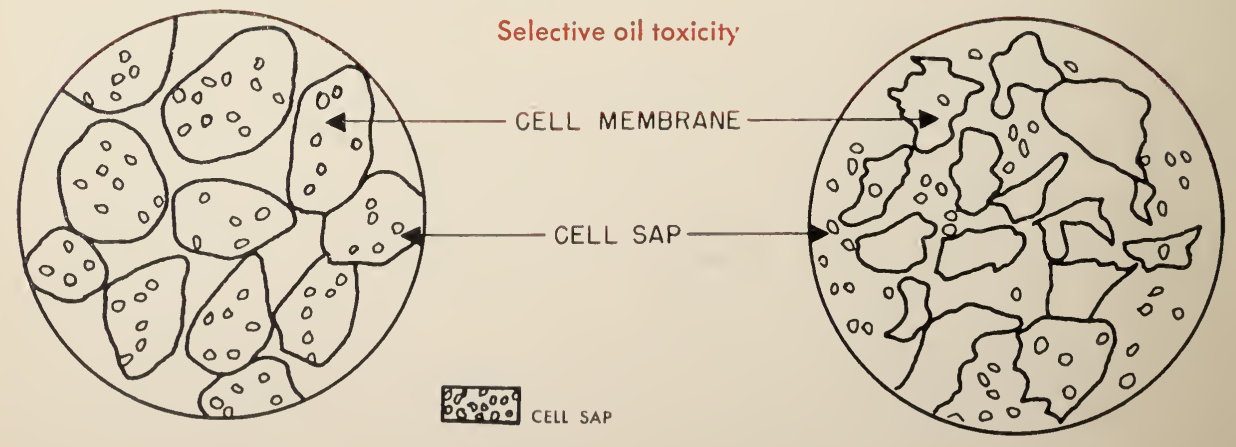

Carrot cell membranes are resistant to selec-

tive oil. Membranes stay intact, keeping cell sap inside.

Weed cell membranes are damaged by selective oil, allowing cell sap to leak into intercellular spaces. 
Blockage of normal enzymatic reaction

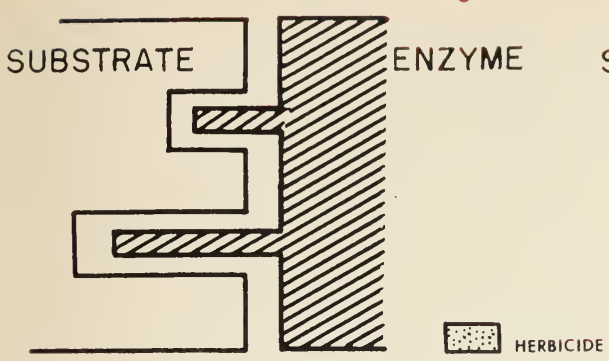

Herbicide does not interfere with enzyme reaction and metabolism.

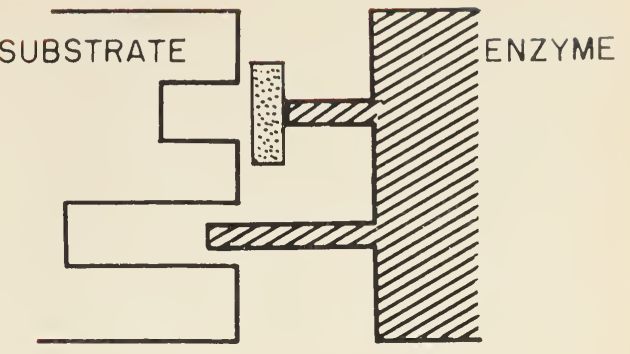

Herbicide alters structure and attachment of enzyme, upsets metabolic processes.

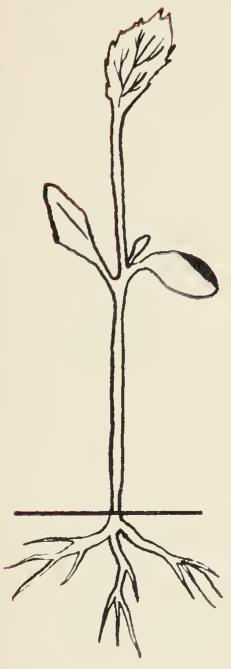

In resistant crop (such as alfalfa) harmless 2,4-DB is not converted to plant killer 2,4-D.

\section{Activation of herbicide}

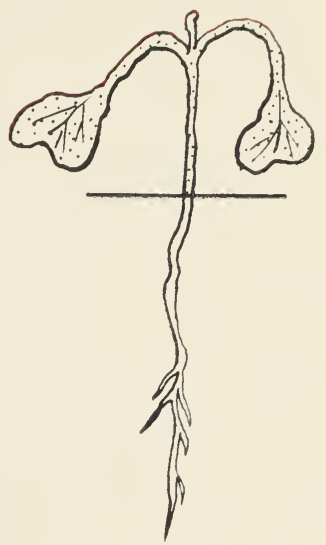

In susceptible weed $2,4-D B$ is converted to 2,4-D.

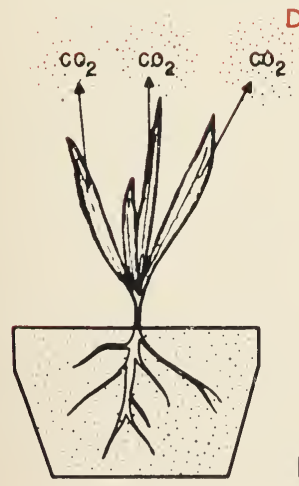

$\square$ HERBICIOE

Decomposition of herbicide

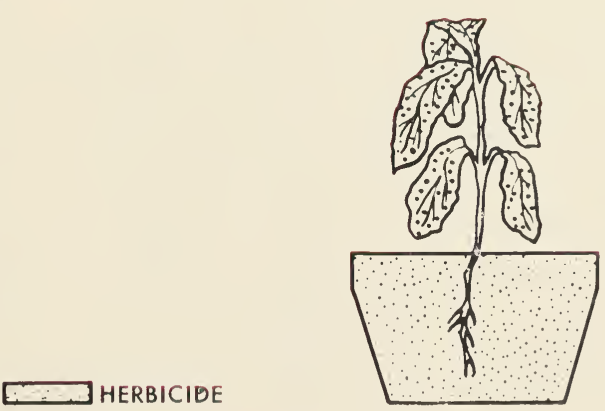

Herbicide simazine is decomposed by corn, liberating $\mathrm{CO}_{2}$ gas and eliminating most of the plant killer.
Simazine is taken up by weed and remains in plant. 
Certain herbicides which are not inherently selective may be made to function selectively because of their position in the soil. Such selectivity depends upon different rooting habits of crop and weed. If you want to remove deep-rooted weeds while leaving shallow-rooted crops intact you must use a herbicide which readily moves beyond the rooting zone of the crop into the rooting zone of the weed. On the other hand, if you want to remove shallow-rooted weeds from a deeprooted crop, you must choose a herbi- cide which remains near the surface of the soil (see drawings below).

Among the factors affecting the movement of herbicides in soil are water solubility of the herbicide, amount of rainfall, and soil type. In general, high water solubility of the herbicide, high amounts of rainfall and light soil types favor a deeper penetration of the herbicide, while low water solubility of the herbicide, low amounts of rainfall and heavy soil types favor a shallower penetration of the herbicide.

BASIS OF SELECTIVITY: Position of herbicide in soil

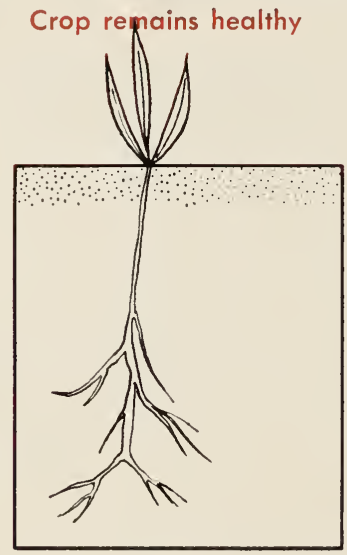

Deep-rooted crop is not affected by herbicide which remains near soil surface.

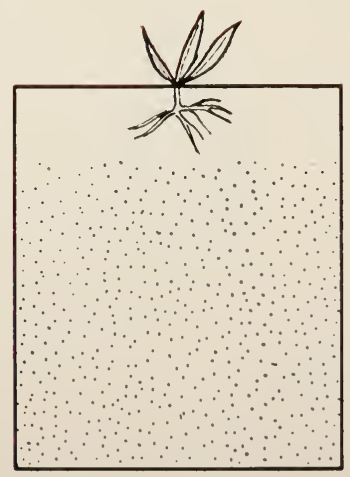

Shallow-rooted crop remains alive if herbicide moves beyond its rooting zone.

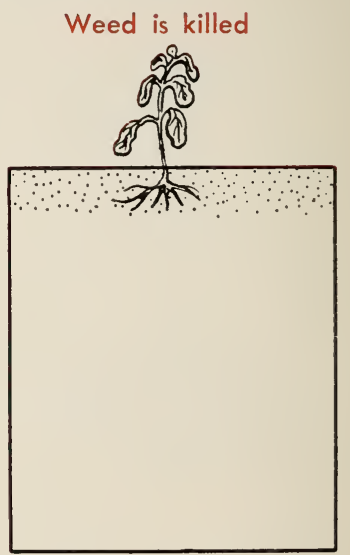

Shallow-rooted weed is killed by herbicide which stays near surface.

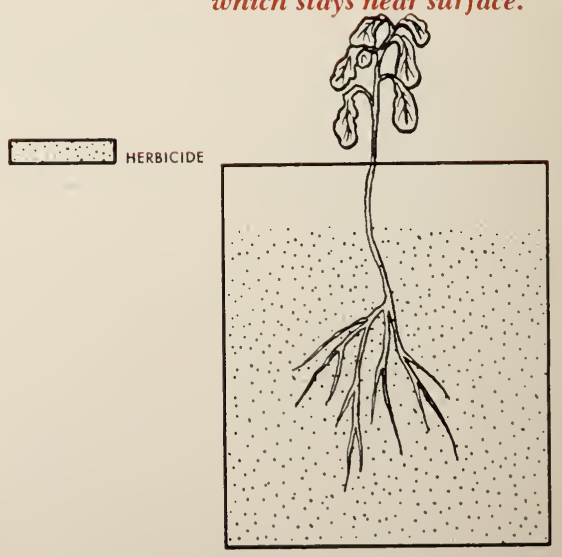

Deep-rooted weed is killed when herbicide is leached into the deeper zones of the soil. 
The herbicide can be applied in such a way that little of it will contact the crop, while much of it will contact the weed. Such selective placement can be accomplished by the use of shielded sprays, directed sprays, or granular formulations (see drawing below and on page 16). The shielded and directed spray methods are normally used with herbicides applied to the leaves; the granular formulations ordinarily are applied to the soil.

In the shielded spray method the shields prevent the herbicidal spray from physically touching the crop while the weeds are covered by the spray. This is accomplished by placing the spray nozzles under a hood, or by covering the crop with a shield.

In the directed spray method only very little herbicide contacts the crop. This is usually accomplished by using drop nozzles between the crop rows. This method is usually used where the crop is higher than the weeds.

Granular material bounces off the crop and falls to the soil surface without sticking to the foliage of the crop. Rainfall or irrigation carries the herbicide into the soil where it is absorbed through the roots and kills young germinating weeds.

BASIS OF SELECTIVITY: Selective Placement

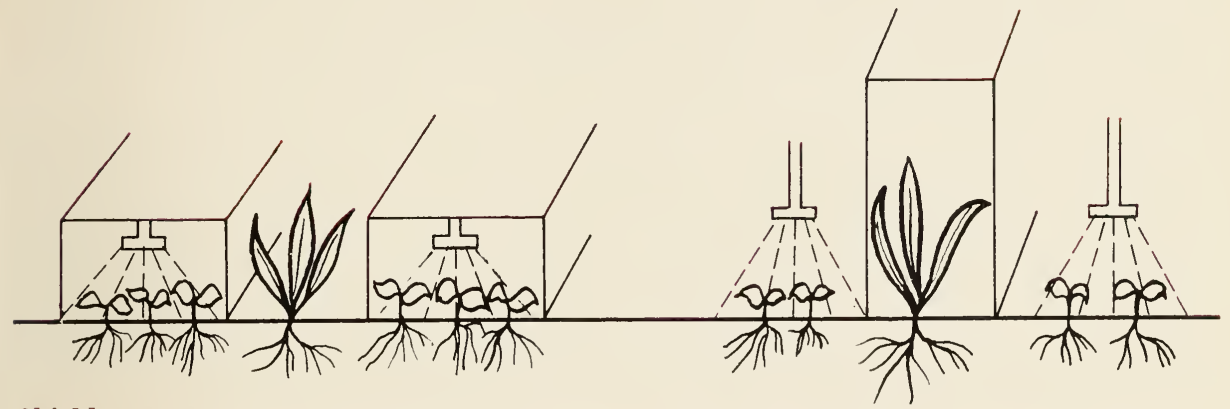

Shielded sprays protect crop from being sprayed with herbicide by having spray confined in shields (left) or crop covered by shields (right).

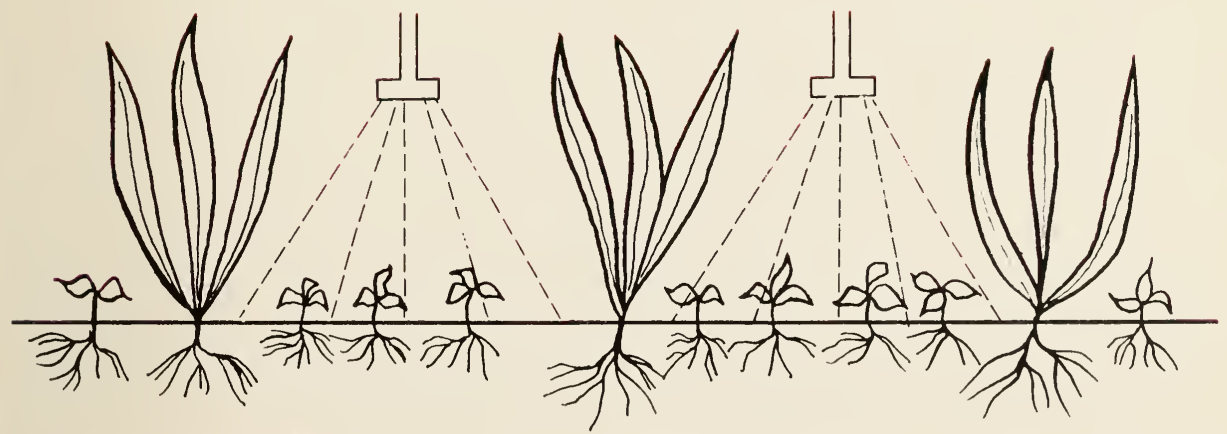

Directed sprays are directed toward base of crop plant, favoring minimum coverage of crop and maximum coverage of weeds. 


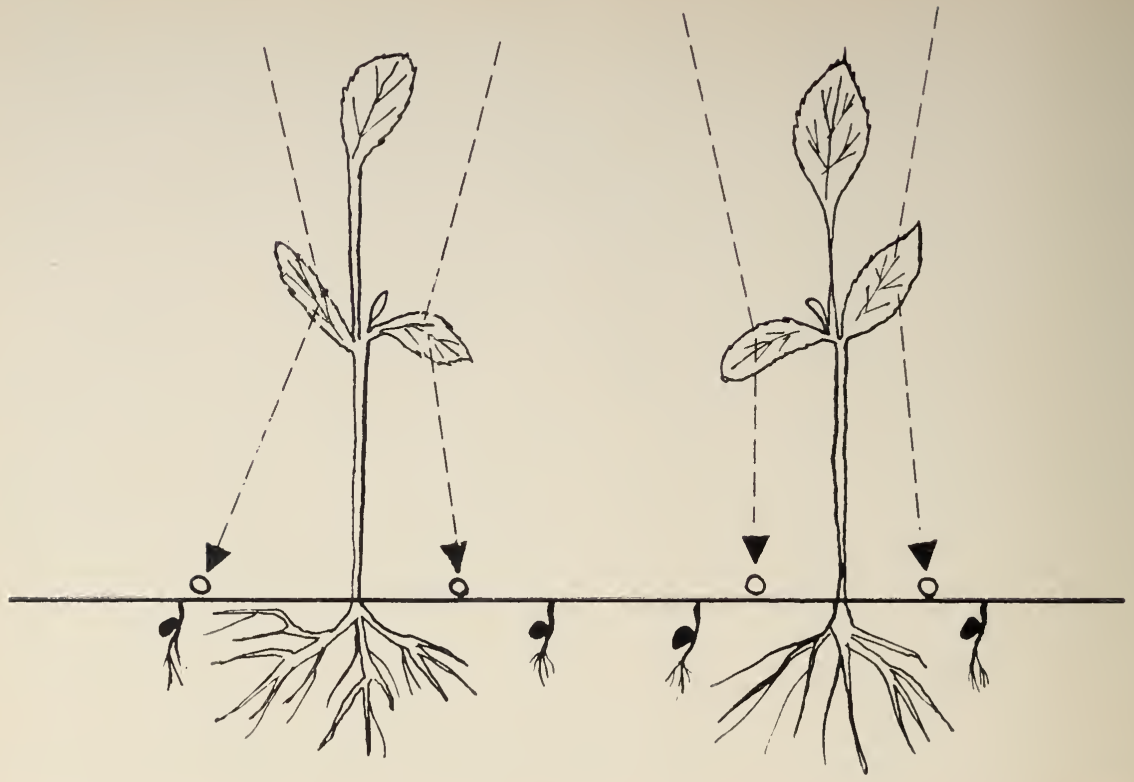

Granular formulation of herbicide allows herbicide to bounce off crop and fall on ground to control germinating weeds.

\section{HOW TO APPLY SELECTIVE HERBICIDES}

As selectivity is relative, it is possible to injure the crop or fail to obtain good weed control if the selective herbicide is not used properly. The following suggestions will minimize your risk.

Read the label-The manufacturers of herbicides have gone to considerable expense and effort to prepare a precise label indicating on what crops the herbicide may safely and legally be used, what weeds it will control, what rates you should use, and what special techniques may be required. Read the label and follow its suggestions.

Find rate of application. You must calibrate the sprayer to obtain the proper rate of application. The rate of application depends upon nozzle spacing on the boom, nozzle pressure, nozzle size, and tractor speed. To determine the volume of spray, run a test and watch for the following:

- Make sure all nozzles are delivering the same amount of spray and producing a uniform pattern; replace those that are not.

- Fill tank with water to a predetermined level.

- Measure off a convenient test distance, such as 500 feet.

- Select a medium tractor speed and nozzle pressure which can be increased or decreased if necessary.

- Start the tractor some distance before the starting marker so that the entire measured distance (500 feet) is traversed at the operating speed. 
Open the boom valve as you pass the starting marker, and close it at the ending marker.

- Measure the width of the spray pattern.

- Refill the tank with water to the predetermined level and measure the number of gallons used.

Use the information gained in this test run in the following formula to calculate how many gallons of the spray you will use per acre:

gallons per acre $=$

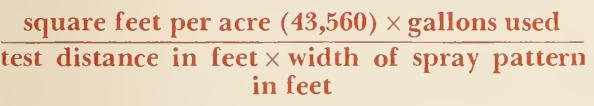

Example:

The sprayer delivered 15 gallons of water over the 500 feet test distance and the spray pattern width was 20 feet wide.

gallons per acre $=$

$$
\frac{43,560 \times 15}{500 \times 20}=65.3 \text { gallons per acre }
$$

If this rate of delivery is not suitable, change nozzle pressure, tractor speed, or both, and recalibrate. Increasing the pressure will increase the rate of delivery, while increasing the tractor speed will decrease the rate. You can also change the rate by changing nozzle size or nozzle spacing on the boom.

Add the recommended amount of herbicide to this volume of spray solution to obtain the desired rate of application. When you use liquid formulations, correct the determined volume for the volume of liquid added in the herbicide formulation.

Watch application rate particularly with granular application. The use of granular formulations of herbicides is relatively new and equipment for such applications is still being perfected. Be extremely careful to obtain the recommended application rate within safe ranges for selectivity.

Avoid drift hazards. The drift of hormonal types of herbicide onto sensitive crops has long been a problem. You can minimize the hazard by using shielded booms and low-pressure nozzles.

Avoid application under extreme conditions. Certain environmental conditions such as rainfall, soil type, temperature, wind, and humidity may strongly affect your weed-control results. Apply herbicides under extreme environmental conditions only if published research results or personal experience indicate that such use is a suitable practice.

Get necessary permits. To insure safe use, permits are required for purchase of certain selective herbicides such as 2,4-D. You may get these permits from your local County Agricultural Commissioner.

Go Slowly. When you first try a selective chemical weed control practice, do it on a limited scale until you have obtained personal experience with it.

TERMS USED IN SELECTIVE WEED CONTROL Absorption-The process by which herbicides are taken into plants, by roots or foliage (stomata, cuticle, etc.).

Annual-A plant that completes its life cycle in one year and then dies. Commonly classified as summer annuals and winter annuals.

Aromatics-Compounds derived from the hydrocarbon benezene $\left(\mathrm{C}_{6} \mathbf{H}_{6}\right)$. 
Band application-An application of spray or dust to a continuous restricted area such as in or along a crop row rather than over the entire field area.

Basal treatment-An application of herbicides to the stems of plants at and just above the ground line.

Biennial-A plant that completes its growth in two years. The first year it produces leaves and stores food; the second year it produces fruits and seeds.

Broadcast (blanket) application-An application of spray or dust over an entire area rather than only on rows, beds, or middles.

Carrier-The liquid or solid material added to a chemical compound to facilitate its storage, shipment, or use in the field.

Compatible-Quality of two compounds that permits them to be mixed without effect on the properties of either.

Concentration-The amount of active material in a given volume of diluent. Recommendations and specifications for concentration of herbicides should be on the basis of pounds per unit volume of diluent.

Contact herbicide-A herbicide that kills primarily by contact with plant tissue rather than as a result of translocation.

Cotyledon leaves-The first leaf, or pair of leaves, of the embryo of seed plants.

Crown-The point where stem and root join in a seed plant.

Directed spray-An application made to minimize the amount of herbicide applied to the crop. This is usually accomplished by setting nozzles low with spray patterns intersecting at the base of the plants just above the soil line.

Emergence-Appearance of the first part of the crop plant through the ground.

Emulsifying agent-A material which facilitates the suspending of one liquid in another.

Emulsion-A mixture in which one liquid is suspended in minute globules in another liquid; for example, oil in water.

Growth stages-(1) Tillering stagewhen a plant produces additional shoots from a single crown, as in wheat. (2) Jointing stage-when the internodes of the stem are elongating. (3) Boot stage-when the seed head of a plant begins to emerge from the sheath-usually applied to the grain crops.

Herbicide-A chemical used for killing plants.

Perennial-A plant that continues to live from year to year. In many cases, in cold climates, the stem dies down but the root persists.

Post-emergence treatment - Treatment made after the crop plants emerge.

Pre-emergence treatment-Treatment made after a crop is planted but before it emerges.

Pre-planting treatment-Treatment made before the crop is planted.

Rate and dosage-These terms are synonymous. "Rate" is the preferred term. Usually refers to the amount of active ingredient material (such 
as 2,4-D acid equivalent) applied to a unit area (such as one acre) reardless of percentage of chemical in the carrier.

Rhizome-Underground stem capable of sending out roots and leafy shoots.

Selective herbicide-A compound which is more toxic to the weeds than to the crop in the field. Helps control weeds without damaging the crop.

Soil sterilant-A material which renders the soil incapable of supporting plant growth. Sterilization may be temporary or practicaly permanent.

Spray drift-The movement of airborne spray particles from the spray nozzle beyond the intended contact area.

Stolon-Runners or stems that develop roots and shoots at the tip or nodes, as in the strawberry plant.

Stool-To throw out shoots; to tiller.
Surfactant -A material which in pesticide formulations imparts emulsifiability, spreading, wetting, dispersability or other surface-modifying properties.

Suspension-A liquid or gas in which very fine solid particles are dispersed, but not dissolved.

Systemic herbicide-A compound which is translocated within the plant and has an effect throughout the entire plant system.

Translocation-Transfer of food or other materials such as herbicides from one plant part to another.

Volatile-Quality which makes a compound evaporate or vaporize (change from a liquid to a gas) at ordinary temperatures on exposure to the air.

Wetting agent-A compound which when added to a spray solution causes it to spread over and wet plant surfaces more thoroughly.

\section{WEED CONTROL PUBLICATIONS}

General Weed Control Practices

General Contact Weed Killer, Circular 447.

University of California Weed Control Recommendations (Revised Annually).

Selective Weed Control With Chemicals

Weed Control in Perennial Legumes, Leaflet 5.

Monuron for Weed Control in Citrus, Leaflet 95.

Weed Control in Rice, Leaflet 97.

Dodder or Dollars, Leaflet.

Dodder and its Control, USDA Farmer's Bulletin 2117.*

Weed Control in Strawberries, One-Sheet Answer, No. 51.

Specific Weed Problems

Poison Oak and Its Control, Leaflet 40.

Field Sandbur and Its Control, Leaflet 55.

Control of Aquatic and Ditchbank Weeds, Circular 158. 
Specific Weed Problems Publications, cont.

The Effect of Drying on Survival of Nutgrass Tubers, Bulletin 751.

Chemical Control of Woody Plants in California, Bulletin 755.

Control of Crabgrass in Home Lawns, One-Sheet Answer No. 5.

Wild Blackberry Control, One-Sheet Answer, No. 23.

Use of Aromatic Solvents for Control of Submersed Aquatic Weeds in Irrigation Channels, USDA Circular No. 971.*

Control of Weedy Grasses in the Garden, Mimeograph.

Johnsongrass Control, One-Sheet Answer, No. 54.

Improving Klamath Weed Ranges, Circular 437.

Equipment for Herbicide Application

When You Buy or Build a Field Sprayer, Agricultural Extension Service Multilith, March 1956.

Spray Rigs You Can Build, Agricultural Extension Service Multilith, September 1957.

Pointers on Low Cost Equipment, Leaflet.

All publications except those of the USDA (marked by *) are obtainable without charge from your Farm Advisor or from Public Service, 131 University Hall, 2200 University Avenue, Berkeley, California, or Public Service, Temporary Building, Room 5, University of California, Davis, California.

For additional information or local recommendations consult the Farm Advisor in your area.

For current recommendations on the use of selective herbicides consult the latest University of California WEED CONTROL RECOMMENDATIONS- these are revised annually and are available from your local Farm Advisor.

In order that the information in our publications may be more intelligible it is sometimes necessary to use trade names of products or equipment rather than complicated descriptive or chemical identifications. In so doing it is unavoidable in some cases that similar products which are on the market under other trade names may not be cited. No endorsement of named products is intended nor is criticism implied of similar products which are not mentioned.

Co-operative Extension work in Agriculture and Home Economics, College of Agriculture, University of California, and L'nited States Department of Agriculture co.operating. Distributed in furtherasce of the Acts of Congress of Slay 8, and June 30, 1914. George B. Alcorn. Director. California Agrieultural Extension Service. 